\title{
Dreaming in NREM Sleep: A High-Density EEG Study of Slow Waves and Spindles
}

\author{
[Drancesca Siclari, ${ }^{1}$ - Giulio Bernardi, ${ }^{1,3}$ Jacinthe Cataldi, ${ }^{1}$ and Giulio Tononi ${ }^{2}$ \\ ${ }^{1}$ Lausanne University Hospital and University of Lausanne, 1011 Lausanne, Switzerland, ${ }^{2}$ Department of Psychiatry, University of Wisconsin-Madison, \\ Madison, Wisconsin 53719, and ${ }^{3}$ MoMiLab Unit, IMT School for Advanced Studies Lucca, 55100 Lucca, Italy
}

Dreaming can occur in both rapid eye movement (REM) and non-REM (NREM) sleep. We recently showed that in both REM and NREM sleep, dreaming is associated with local decreases in slow wave activity (SWA) in posterior brain regions. To expand these findings, here we asked how specific features of slow waves and spindles, the hallmarks of NREM sleep, relate to dream experiences. Fourteen healthy human subjects (10 females) underwent nocturnal high-density EEG recordings combined with a serial awakening paradigm. Reports of dreaming, compared with reports of no experience, were preceded by fewer, smaller, and shallower slow waves, and faster spindles, especially in central and posterior cortical areas. We also identified a minority of very steep and large slow waves in frontal regions, which occurred on a background of reduced SWA and were associated with high-frequency power increases (local "microarousals") heralding the successful recall of dream content. These results suggest that the capacity of the brain to generate experiences during sleep is reduced in the presence of neuronal off-states in posterior and central brain regions, and that dream recall may be facilitated by the intermittent activation of arousal systems during NREM sleep.

Key words: consciousness; dream; high-density EEG; sleep; slow wave

\section{Significance Statement}

By combining high-density EEG recordings with a serial awakening paradigm in healthy subjects, we show that dreaming in non-rapid eye movement sleep occurs when slow waves in central and posterior regions are sparse, small, and shallow. We also identified a small subset of very large and steep frontal slow waves that are associated with high-frequency activity increases (local "microarousals") heralding successful recall of dream content. These results provide noninvasive measures that could represent a useful tool to infer the state of consciousness during sleep.

\section{Introduction}

What determines the level of consciousness during sleep? Why are we sometimes unconscious, while at other times we have vivid conscious experiences in the form of dreams? When rapid eye movement (REM) sleep was first described in humans (Aserinsky and Kleitman, 1955), the explanation seemed relatively straightforward: $74 \%$ of subjects woken up during this state reported that

\footnotetext{
Received March 29, 2018; revised July 30, 2018; accepted Aug. 1, 2018.

Author contributions: F.S. and G.T. designed research; F.S. and J.C. performed research; F.S. and G.B. analyzed data; F.S. wrote the paper.

This work was supported by Swiss National Science Foundation Grant PZ00P3_173955 (F.S.), the Divesa Foundation Switzerland (F.S.), the Pierre-Mercier Foundation for Science (F.S.), the Bourse Pro-Femme of the University of Lausanne (F.S.), an EMBO short-term postdoctoral fellowship (G.B.), National Institutes of Health (NIH)/National Center for Complementary and Alternative Medicine Grant P01-AT-004952 (G.T.), NIH/National Institute of Mental Health Grant 5P20-MH-077967 (G.T.), and the Tiny Blue Dot Inc. Grant MSN196438/AAC1335 (G.T.).

The authors declare no competing financial interests.

Correspondence should be addressed to Francesca Siclari, Center for Research and Investigation in Sleep (CIRS), Lausanne University Hospital (CHUV), Rue du Bugnon 46, 1011 Lausanne, Switzerland. E-mail: francesca.siclari@chuv.ch.

DOI:10.1523/JNEUROSCI.0855-18.2018

Copyright $\odot 2018$ the authors $\quad 0270-6474 / 18 / 389175-11 \$ 15.00 / 0$
}

they had been dreaming, compared with only $17 \%$ awakened at other times. It is not surprising that following this observation, Aserinsky and Kleitman (1955) claimed to have "furnished the means of determining the incidence and duration of periods of dreaming." Indeed, the fast-frequency, desynchronized EEG activity of REM sleep, similar to the waking EEG, appeared to offer the ideal premises for conscious experiences to occur. In the following years, however, the assumption that dreaming and conscious experiences were synonymous with REM sleep was challenged (Solms, 2000). Pharmacological suppression of REM sleep, for instance, did not eliminate dreaming (Oudiette et al., 2012), and specific forebrain lesions (Solms, 2000) were shown to suppress dreaming without affecting REM sleep. In addition, by changing the question from "Tell me whether you had a dream" to "Tell me what was going through your mind," reports of conscious experiences in non-REM (NREM) sleep were obtained in up to $70 \%$ of cases (Stickgold et al., 2001). Especially in the early morning hours, NREM sleep dream reports appeared indistinguishable from REM sleep dream reports (Monroe et al., 1965; Antrobus et al., 1995). This raised the question of whether slow 
waves, which decrease across the night as a function of homeostatic sleep pressure, may interfere with the generation of dream experiences (DEs). Experimental and theoretical work offers plausible explanations of why this should be so: neuronal "offperiods" associated with slow waves disrupt causal interactions between thalamocortical regions (Massimini et al., 2005; Pigorini et al., 2015), thereby impairing information integration, which has been proposed as a prerequisite for consciousness (Tononi, 2008). Initial attempts to relate EEG changes in slow-wave activity (SWA; spectral power, $1-4 \mathrm{~Hz}$ ) to dreaming yielded variable results (Williamson et al., 1986; Esposito et al., 2004; Chellappa et al., 2011; Marzano et al., 2011). In recent years, it has become clear that the alternation between off-periods and "on-periods" underlying the surface EEG slow wave is not global, but occurs mostly locally, meaning that it can occur out of phase with respect to other cortical regions (Nir et al., 2011). It has also become clear that conventional EEG recordings comprising only a few electrodes would not be able to capture such local SWA changes. In addition, slow waves with neuronal off-periods have been shown to occur not only in NREM sleep, but also in superficial cortical layers of primary sensory cortices in REM sleep in mice (Funk et al., 2016). To account for these aspects, in a recent study we used high-density EEG (hd-EEG) to investigate changes in brain activity associated with dreaming. We demonstrated that reports of dreaming were preceded by decreases in SWA in both REM and NREM sleep. These decreases were not global, but spatially restricted to a "posterior hot zone" of the brain, suggesting that local changes in SWA may account for the presence of dreaming or unconsciousness across different behavioral states. Here we aimed to extend these findings. Instead of assessing spectral power, a rough estimate of both slow-wave number and amplitude, we investigated how specific characteristics of slow waves relate to dreaming. Indeed, specific slow-wave features have been shown to reflect different aspects of neuronal oscillations (Esser et al., 2007; Riedner et al., 2007; Vyazovskiy et al., 2007), including the degree of cortical bistability (density), the number of neurons that simultaneously enter a down-state (amplitude), and synaptic strength (slope). Based on these criteria, we were recently able to characterize two types of slow waves (Siclari et al., 2014; Bernardi et al., 2018): widespread, steep, and largeamplitude type I slow waves in frontocentral brain regions that are likely generated by a subcorticocortical synchronization process; and type II slow waves with a smaller amplitude and slope and a more variable regional involvement, which are likely generated by a corticocortical synchronization process. To determine how these two types of slow waves relate to dreaming, and to extend our findings to sleep spindles, we analyzed high-density EEG recordings of 14 healthy participants who underwent a serial awakening paradigm.

\section{Materials and Methods}

Participants and procedure. Fourteen healthy participants (mean $\pm \mathrm{SD}$ age, $33.6 \pm 8.5$ years; age range, $22-47$ years; 10 females) screened for medical, neurological, and psychiatric disorders participated in the study. None of the subjects was receiving psychotropic medication. All of the participants had good sleep quality, as assessed by the Pittsburgh Sleep Quality Index ( $<5$ points), and scored within normal limits on the Epworth Sleepiness Scale. Dream characteristics and spectral power changes associated with dreaming in the delta $(1-4 \mathrm{~Hz})$ and gamma $(20-50 \mathrm{~Hz})$ frequency ranges of subjects $1-7$, but not slow-wave or spindle findings, have been previously reported (experiment 2; Siclari et al., 2017), while subjects $8-14$ were newly included. Subjects $1-7$ were acquired at the University of Wisconsin-Madison, while subjects 8-14 were studied at the Lausanne University Hospital. Written informed consent was obtained from each participant, and the study was approved as part of a larger project by the local ethical committees (University of Wisconsin Madison and Lausanne University Hospital). Participants were recorded with hd-EEG (256 electrodes) while they slept in the sleep laboratory. Throughout the night, they were awakened repeatedly (Siclari et al., 2013) and asked to report whether, just before the awakening, they had been experiencing anything (DE), had been experiencing something but could not remember the content [DE without recall of content (DEWR)] or had not been experiencing anything [no experience (NE); Siclari et al., 2013]. The serial awakening protocol has previously been reported in detail (Siclari et al., 2013). Awakenings were performed using a computerized alarm sound lasting $1.5 \mathrm{~s}$.

All subjects were studied by the first author of this article and underwent the same serial awakening paradigm (Siclari et al., 2013), except for the fact that University of Wisconsin-Madison subjects were studied for 5-10 nights while Lausanne University Hospital subjects underwent only 2 study nights. As a consequence, University of Wisconsin-Madison subjects had more total awakenings compared with Lausanne University Hospital subjects ( $113.6 \pm 26.0$ vs $24.86 \pm 8.23$ per subject; $p<0.001$, unpaired two-tailed $t$ tests). No differences between the two groups were observed in the proportion of NREM sleep awakenings with respect to total awakenings ( $75.00 \pm 5.30 \%$ vs $78.81 \pm 2.60 \%)$; in the proportion of $\mathrm{N} 2$ or N3 awakenings with respect to NREM $(\mathrm{N} 2+\mathrm{N} 3)$ awakenings $(55.9 \pm 13.69 \%$ vs $53.45 \pm 22.71 \% \mathrm{~N} 2$ awakenings, $p=0.81)$; and in the proportion of DEs $(30.96 \pm 14.49 \%$ vs $34.13 \pm 20.64 \%, p=0.74)$, DEWRs ( $38.55 \pm 13.88$ vs $40.30 \pm 21.40, p=0.86)$, and NE (30.50 \pm 21.75 vs $24.97 \pm 24.69, p=0.66)$ in NREM sleep. The study groups did not differ significantly in terms of age $(31.57 \pm 8.5 \mathrm{vs} 35.71 \pm 8.6$ years of age; $p=0.38$ ) and female/male distribution (4/7 vs $5 / 7$ females/males; $p=0.57$, Pearson's $\chi^{2}$ test). All of the comparisons reported herein were performed within subjects.

Recordings. Sleep recordings were performed using a 256-channel hdEEG system (Electrical Geodesics). Four of the 256 electrodes placed at the outer canthi of the eyes were used to monitor eye movements, and submental electromyography was recorded using the Electrical Geodesics polygraph input box. The EEG signal was sampled at $500 \mathrm{~Hz}$, and was off-line bandpass filtered between 0.3 and $50 \mathrm{~Hz}$ for the first set of participants (subjects 1-7) and between 0.3 and $45 \mathrm{~Hz}$ for the second set of participants (subjects $8-14$, because of the different frequencies of electrical artifacts in the United States and Europe). All of the analyses were performed on frequency bands available for both studies $(<40 \mathrm{~Hz})$. Sleep scoring was performed over $30 \mathrm{~s}$ epochs according to standard criteria (Iber et al., 2007).

Preprocessing of data. The signal corresponding to the 2 min preceding each awakening in stages N2 and N3 was extracted and considered for analysis. Channels containing artifactual activity were visually identified and replaced with data interpolated from nearby channels using spherical splines (NetStation, Electrical Geodesic). To remove ocular, muscular, and electrocardiograph artifacts, we performed independent component analysis (ICA) using EEGLAB routines (Delorme and Makeig, 2004). Only ICA components with specific activity patterns and component maps characteristic of artifactual activity were removed (Jung et al., 2000).

Slow-wave detection. For slow-wave detection, we used an automatic detection algorithm that was adapted from a previous study (Siclari et al., 2014). The EEG signal was referenced to the average of the two mastoid electrodes, downsampled to $128 \mathrm{~Hz}$, and bandpass filtered $(0.5-4 \mathrm{~Hz}$; stop-band at 0.1 and $10 \mathrm{~Hz}$ ) using a Chebyshev Type II filter (Matlab, MathWorks). Only slow waves with a duration between 0.25 and $1 \mathrm{~s}$ were considered. The algorithm was applied to all channels, and the following slow-wave parameters were analyzed: density, negative peak amplitude, slope 1 (between the first zero crossing and the negative peak), slope 2 (between the negative peak and the second zero crossing), and the number of negative peaks. For an initial, explorative analysis, we considered large-amplitude slow waves separately from other slow waves. Large- 


\section{DREAM EXPERIENCE VS NO EXPERIENCE (ALL SLOW WAVES)}

Density

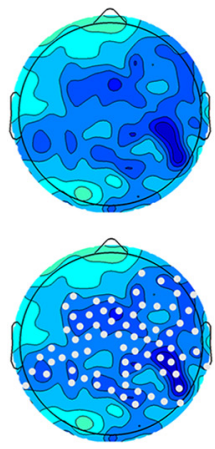

Amplitude
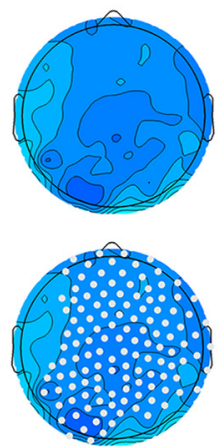

Slope 1
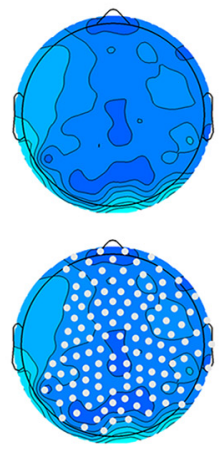

T VALUES dream experience $<$ no experience

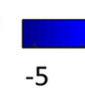

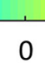

Slope 2
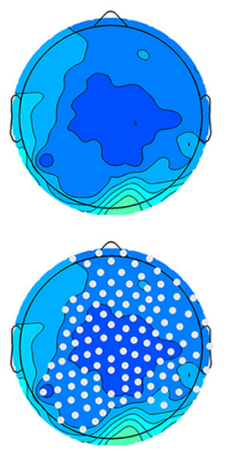

dream experience $>$ no experience

Figure 1. Top row, Topographical distribution of $t$ values for the contrast between dream experiences and no experiences for different slow-wave parameters, averaged over the last $60 \mathrm{~s}$ before the awakening. Bottom row, Same as the top row, but electrodes within a cluster showing a statistically significant effect are marked in white $(p<0.05$, cluster-based correction for multiple comparisons, two-tailed paired $t$ tests; $n=12$ subjects).

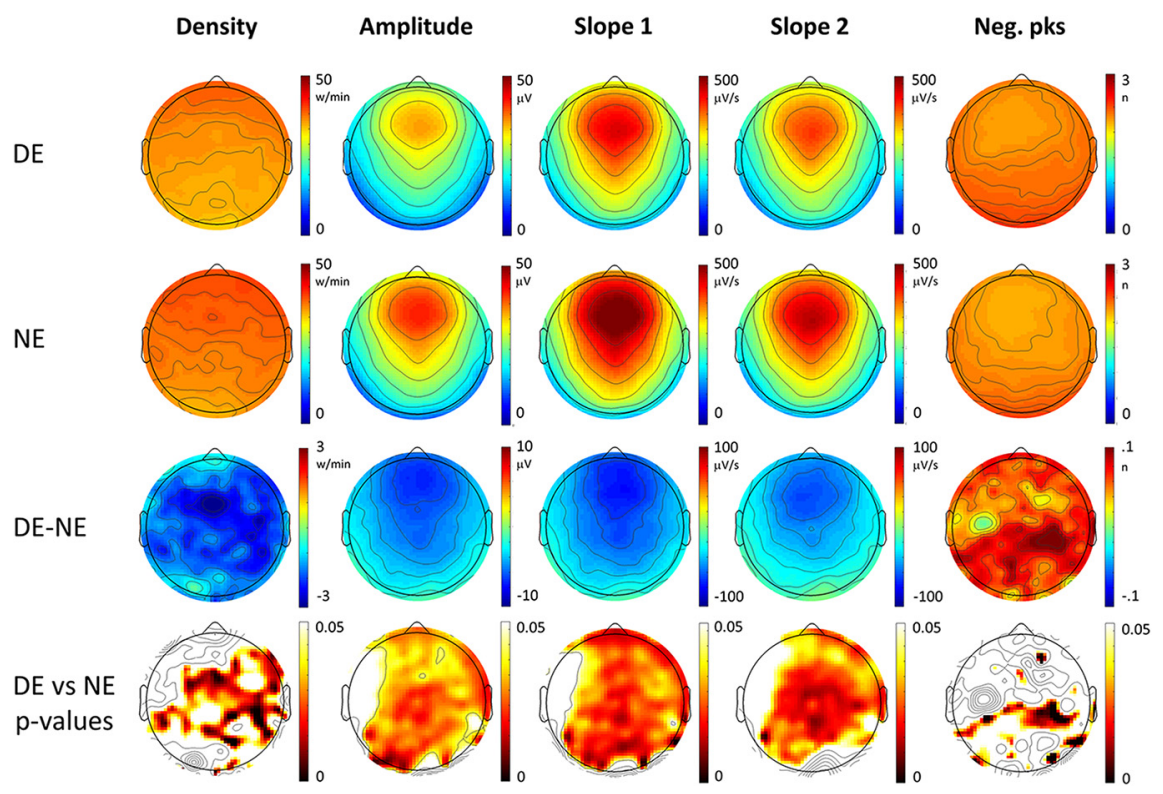

Figure 2. Top row, Topographical distribution of slow-wave parameters for dream experiences (DES) (first row) and no experiences (NEs) (second row). Slow-wave parameters were averaged over the last $60 \mathrm{~s}$ before the awakening and across 12 subjects. In the third row, the mean differences between DE and NE (DE - NE) are shown for each parameter, so that red colors indicate higher values in $\mathrm{DE}$, and blue colors higher values in NE. In the fourth row, $p$ values for paired electrode-by-electrode $t$ tests are shown ( $p<0.05$, uncorrected).

amplitude slow waves ( $>75$ th percentile) were identified for each subject separately by determining the amplitude corresponding to the 75th percentile of the amplitude distribution of all slow waves (all of the 2 min segments preceding awakenings in $\mathrm{N} 2$ and N3 were concatenated for this analysis).

Separation between type I and type II slow waves. Then, for a more precise separation between type I and type II slow waves, we used a previously described approach (Bernardi et al., 2018), which also has the advantage that it can classify slow waves irrespective of their topographical distribution. We first created a single timing reference. To do this, the negative signal envelope was generated by selecting the fifth most negative sample across all mastoid-referenced channels for each time point. The fifth most negative channel was arbitrarily selected instead of the most negative channel to avoid including residual highamplitude artifacts (Siclari et al., 2014; Bernardi et al., 2016). Then, a slow-wave detection procedure was applied to this composite signal after bandpass filtering $(0.5-40 \mathrm{~Hz})$. To distinguish between type I and type II slow waves, for each detection we calculated a synchronization score defined as the scalp involvement (expressed as the percentage of channels showing a negative averaged current value less than -5 $\mu \mathrm{V}$ in the $40 \mathrm{~ms}$ time window centered on the wave peak) multiplied by the mean slope of the slow wave (i.e., the mean of slope 1 and slope 2; Bernardi et al., 2018). The $5 \mu \mathrm{V}$ criterion is an arbitrary cutoff to exclude small baseline fluctuations that are likely unrelated to slow waves (Siclari et al., 2014; Bernardi et al., 2016). Based on the distribution of the synchronization scores of all the slow waves in N2 and N3, we defined an absolute threshold that corresponded to 4 median absolute deviations (MADs) from the median. This threshold was calculated for each subject separately. Type I slow waves were defined as slow waves characterized by a synchronization score greater than the threshold, while the remaining slow waves were classified as type II.

Spectral power analysis. To calculate spectral power changes associated with type I and type II slow waves, we computed power spectral density (PSD) for each channel in the following two $6 \mathrm{~s}$ periods: a prewave period (ending $1 \mathrm{~s}$ before the first zero crossing of the slow wave detected in the composite reference signal) and a postwave period (starting $1 \mathrm{~s}$ after the second zero crossing of the slow wave). Spectral power was calculated in $2 \mathrm{~s}$ Hamming windows using the Welch's modified periodogram method (implemented with the pwelch function in Matlab). We then averaged prewave and postwave spectral power across the three $2 \mathrm{~s}$ bins for each channel. To evaluate changes in spectral power induced by type I and type II slow waves, we subtracted postwave power from the prewave power and expressed the changes as a percentage, so that positive values represent increases in postwave with respect to prewave power, while negative values represent decreases in postwave with respect to prewave power. All of the analyses were performed within subjects first, then averaged across subjects.

Source modeling. To evaluate the cortical localization of high-frequency power increases after type I slow waves, a source modeling analysis of the $18-30 \mathrm{~Hz}$ bandpass-filtered signal was performed using GeoSource 3.0 (NetStation, Electrical Geodesics). A four-shell head model based on the Montreal Neurological Institute atlas and standard electrode coordinates were used to construct the forward model. The inverse matrix was defined using the standardized low-resolution brain electromagnetic tomography method (Tikhonov regularization, $\lambda=10^{-2}$ ). The source-modeling analysis was performed on $6 \mathrm{~s}$ windows preceding and following type I slow waves, and root mean square values in the specified frequency range were used to compute relative postwave-pre- 
wave variations. These values were averaged across slow waves and subjects.

Spindle detection. Spindle detection was based on an automatic algorithm, adapted from a previous study (Ferrarelli et al., 2007). The averagereferenced signal was downsampled to $128 \mathrm{~Hz}$ and bandpass filtered between 11 and $16 \mathrm{~Hz}$ $(-3 \mathrm{~dB}$ at 10 and $17 \mathrm{~Hz})$. The following spindle parameters were analyzed: density, maximal amplitude, and frequency. Based on a previous studies (Anderer et al., 2001; Andrillon et al., 2011; Molle et al., 2011), we categorized spindles as fast or slow based on an individualized threshold, which was defined as the intermediate value between the average spindle frequency in one centroparietal channel $(\mathrm{Pz})$ and one frontal channel (Fz; Siclari et al., 2014).

Experimental design and statistical analysis. Statistical analyses were performed in Matlab (MathWorks). Analyses regarding general slowwave properties (see Figs. 7, 8C-E) were performed on the totality of the available signal ( 120 $s$ before the awakening), while analyses referring to dream reports (i.e., comparisons among DE, NE, and DEWR shown in Figs. 1, 2, 3, 4, 5, 6; see also Figs. $8 B, 10,11)$ were performed on slowwave and spindle parameters in the $60 \mathrm{~s}$ before the awakening. Topographical analyses were limited to the 185 innermost channels to avoid the common artifactual contamination of electrodes located on the cheeks and neck.

To compare brain activity between DE and NE (and DEWR, when applicable), slow-wave and spindle parameters were first averaged within the $60 \mathrm{~s}$ preceding each awakening for each subject. We then averaged the slow-wave and spindle parameters associated with DEs and NEs within each subject. Whole-brain group-level comparison on average slow wave and spindle were performed using a clusterbased correction for multiple comparisons (Nichols and Holmes, 2002). Two-tailed paired $t$ tests with a corrected $p<0.05$ threshold were performed. The number of subjects for each comparison is indicated in the figure legends. Correction for multiple comparisons was ensured using a permutation-based suprathreshold cluster analysis (Nichols and Holmes, 2002; Huber et al., 2004). In brief, for each comparison new datasets were generated by randomly relabeling the condition label from original data and paired $t$ tests were performed $(N=5000)$. For each iteration, the maximal size of the resulting significant clusters of electrodes was stored to generate a cluster size distribution. Then, the 95th percentile of this distribution was used as the critical cluster-size threshold to achieve cluster-corrected $p$ values corresponding to $\alpha<0.05$. We did not perform an additional correction for multiple comparisons based on the number of contrasts for slow-wave and spindle parameters because many of these are not truly independent, but are highly correlated.

To investigate the correlation between slow-wave amplitude in frontal and occipital regions (Fig. 7), we first averaged, for each 2 min data segment, slow-wave amplitude within the following two regions of interest: $\mathrm{Fz}$ and $\mathrm{Oz}$ (occipital), and immediately adjacent electrodes. We then correlated these frontal and occipital values within subjects by taking account of all the NREM segments (Spearman rank correlation). Statistical significance was determined using a permutation-based approach.

\section{DREAM EXPERIENCE w/o RECALL of CONTENT VS NO EXPERIENCE (ALL SLOW WAVES)}

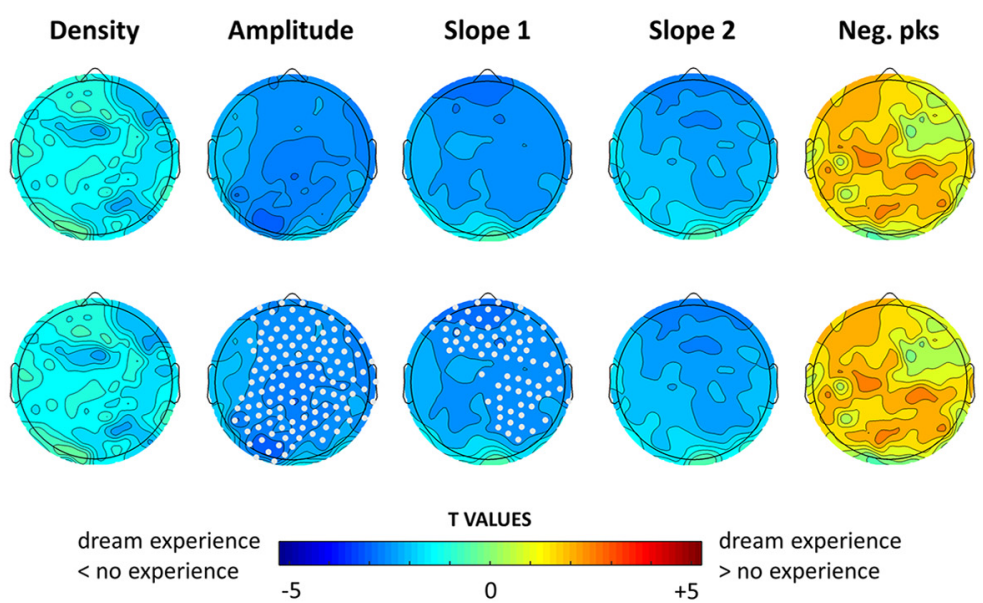

Figure 3. Top row, Topographical distribution of $t$ values for the contrast between dream experiences without recall of content and no experiences for different slow-wave parameters averaged over the last 60 s before the awakening. Bottom row, Same as the top row, but electrodes within a cluster showing a statistically significant effect are marked in white $(p<0.05$, cluster-based correction for multiple comparisons, two-tailed paired $t$ tests; $n=12$ subjects).

\section{DREAM EXPERIENCE VS NO EXPERIENCE (LARGE SLOW WAVES)}

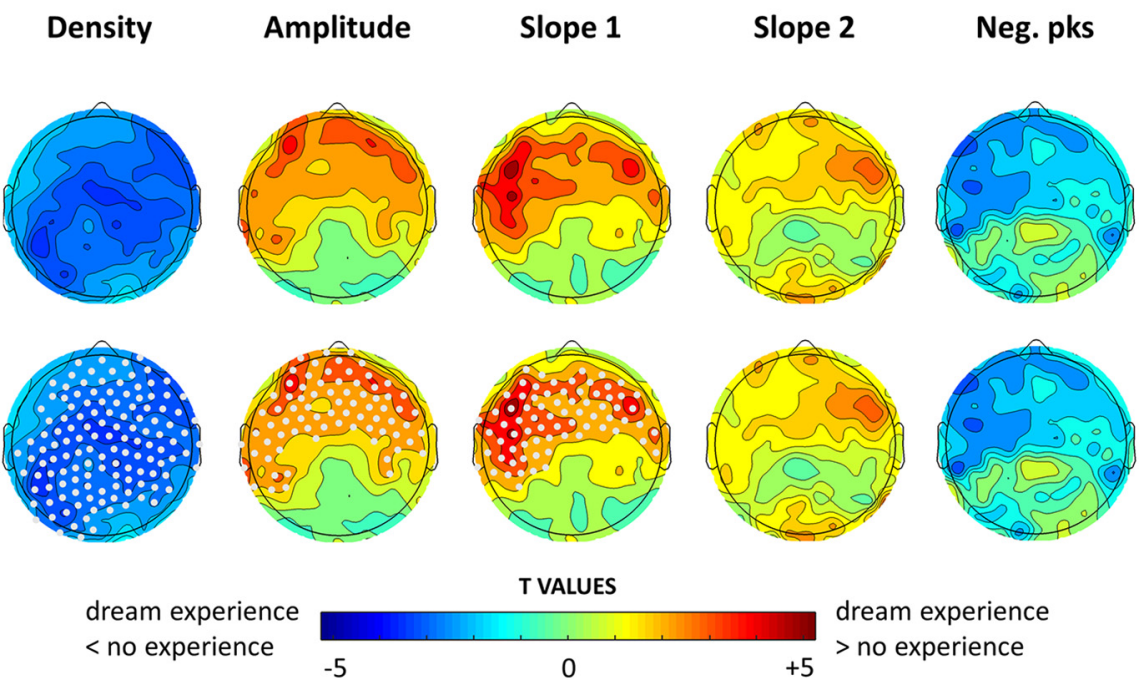

Figure 4. Top row, Topographical distribution of $t$ values for the contrast between dream experiences and no experiences for the 75th amplitude percentile (across all slow waves detected in NREM sleep) were included. Bottom row, Same as the top row, but electrodes within a cluster showing a statistically significant effect are now marked in white $(p<0.05$, cluster-based correction for multiple comparisons, two-tailed paired $t$ tests; $n=12$ subjects).

Specifically, null distributions with properties that are comparable to those of the original (real) distributions were generated by randomly shuffling the two variables of interest (frontal and occipital amplitude of slow waves) in each subject (using all available data segments) and recalculating the group-level mean correlation $(n=1000)$. This null distribution was then used to calculate the significance level of real group-level correlation values $(p<0.05)$. The same procedure was performed to test the correlation between the amplitude of large frontal slow waves $(>75$ th percentile) and occipital slow waves (without an amplitude threshold).

For the correlation between the synchronization index of type I and type II slow waves and the preceding SWA (Fig. $8 C$ ), we extracted, for each channel, the power spectral density in the $6 \mathrm{~s}$ window preceding each type I and type II slow wave detected in the reference signal. We then 


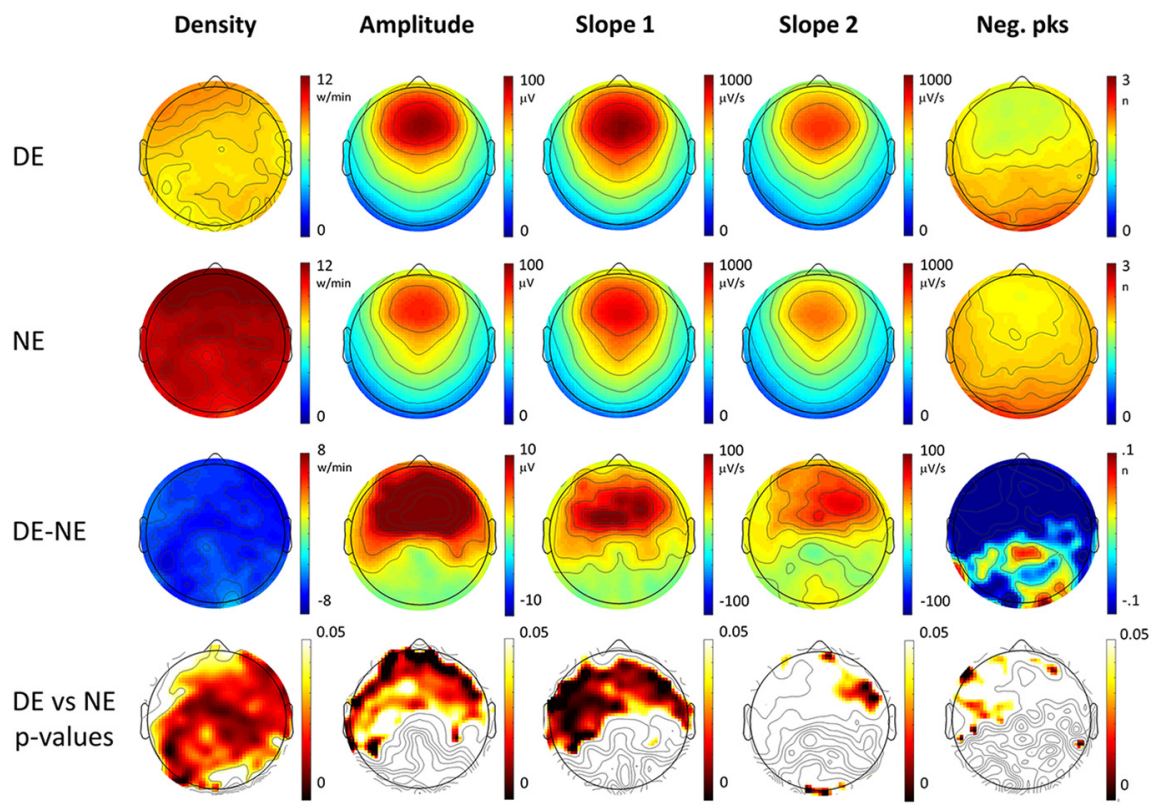

Figure 5. Top row, Topographical distribution of slow-wave parameters for DEs (first row) and NEs (second row). Slow-wave parameters were averaged over the last $60 \mathrm{~s}$ before the awakening and across 12 subjects. In the third row, the mean differences between dream experiences (DES) and no experiences (NES) (DE - NE) are shown for each parameter, so that red colors indicate higher values in $\mathrm{DE}$, and blue colors higher values in NE. In the fourth row, $p$ values for paired electrode-by-electrode $t$ tests are shown ( $p<0.05$, uncorrected). Here only slow waves larger than the 75 th amplitude percentile were included for each subject.

\section{DREAM EXPERIENCE WITH VS. WITHOUT RECALL Of CONTENT (LARGE SLOW WAVES)}
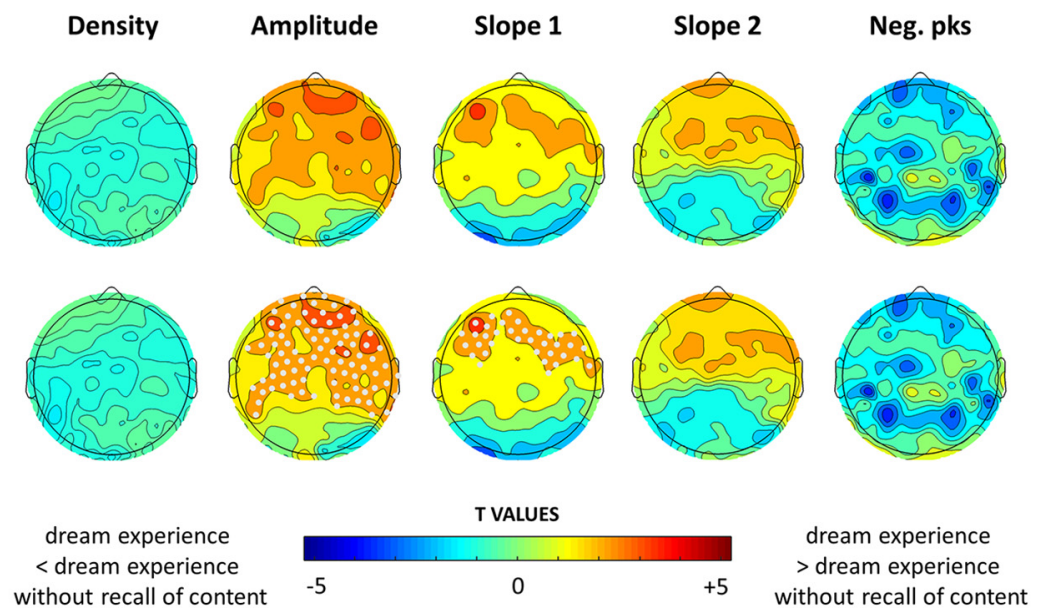

Figure 6. Top row, Topographical distribution of $t$ values for the contrast between dream experiences and dream experiences without recall of content for different slow-wave parameters averaged over the last $60 \mathrm{~s}$ before the awakening. For each subject, only slow waves larger than the 75th amplitude percentile were included. Bottom row, Same as the top row, but electrodes within a cluster showing a statistically significant effect are marked in white $(p<0.05$, cluster-based correction for multiple comparisons; $n=14$ subjects).

correlated spectral power and the synchronization index for each subject and channel using a Spearman rank correlation. Statistical significance was determined using the same permutation-based approach described above.

\section{Results}

Of the 969 awakenings performed across all subjects, 735 were performed in NREM sleep stages N2 and N3. Of these, 246 (33.5\%) yielded reports of DE, 284 (38.6\%) of DEWR, and 204 $(27.8 \%)$ of NE. Two subjects did not present NE in NREM sleep.
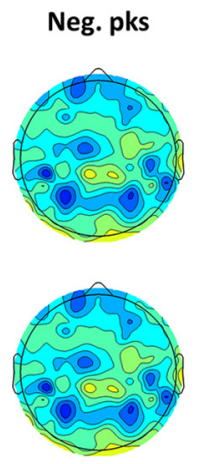

\section{Slow waves and dreaming}

Slow waves preceding reports of DE, compared with NE, were significantly less numerous, had a smaller amplitude and slope (corrected $p<0.05$ ) and displayed a trend toward more negative peaks (uncorrected $p<0.05)$. These differences were relatively widespread, but the strongest statistical effects were observed in posterior and central brain regions (Fig. 1, see Fig. 2 for mean absolute values, mean differences and uncorrected statistics). Similar results for amplitude and slope were obtained when comparing DEWR and NE (Fig. 3), while the contrast between DE and DEWR did not yield any significant differences (data not shown), suggesting that these findings reflect differences in dreaming, and not in the ability to recall the content of the dream.

Next, based on our previous work, in which we identified two types of slow waves that differ in amplitude, we performed an explorative analysis focusing exclusively on high-amplitude slow waves, using an arbitrary minimal threshold corresponding to the 75 th percentile of the negative peak. This threshold was calculated for each channel and subject separately, by considering all the detected slow waves in NREM sleep. Consistent with the previous analysis (Fig. 1), reports of DE were preceded by fewer high-amplitude slow waves compared with NE, particularly in central and posterior brain areas (Fig. 4). However, DEs were also associated with significantly larger and steeper high-amplitude slow waves in frontal regions (corrected $p<0.05$; Fig. 4 , see Fig. 5 for mean absolute values, mean differences and uncorrected statistics), which displayed a trend toward fewer negative peaks (uncorrected $p<0.05$ ). An additional analysis (Fig. 6) revealed that frontal high-amplitude slow waves were even larger and steeper when the content of the dream could be recalled (DE), as opposed when to when subjects reported dreaming but could not remember the content (DEWR), while no significant differences were found between DEWR and NE (data not shown).

Together, these results suggest that dream experiences are more likely to occur when slow waves are sparse, small, and shallow, particularly in posterior and central brain regions. In addition, by applying a minimal-amplitude threshold, we identified a small minority of very steep, high-amplitude slow waves in anterior cortical regions that tend to precede reports of dream experiences with recall of content.

Since we showed that dreaming tends to occur when slowwave amplitude in posterior regions is low (Fig. 1), we asked whether the frontal high-amplitude slow waves were associated 

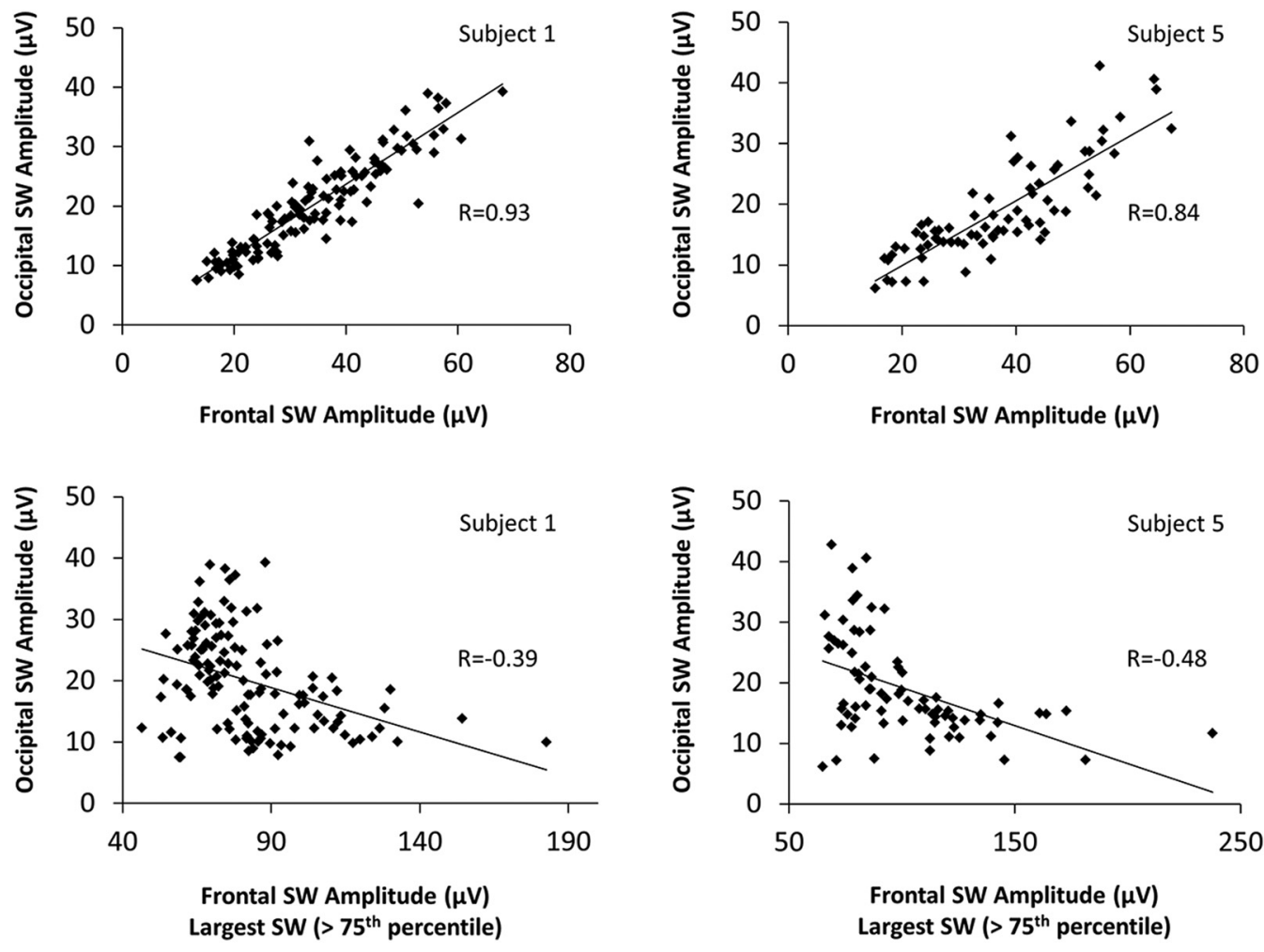

Figure 7. Correlation between slow-wave amplitude in a frontal and occipital region of interest for two representative subjects. Top row, All slow waves (no amplitude threshold). Bottom row, An amplitude threshold (above the 75th percentile of all waves for each subject) was applied to frontal slow waves.

with reductions in slow-wave amplitude in posterior areas. To this aim, we first tested the correlation between the amplitude of slow waves (without an amplitude threshold) detected in a frontal region ( $\mathrm{Fz}$ and immediately neighboring electrodes) and an occipital region of interest $(\mathrm{Oz}$ and immediately neighboring electrodes) for all 2 min NREM segments in each subject. This analysis revealed, as expected, a strong positive correlation between the amplitude of frontal and occipital slow waves (Spearman rank correlation coefficient $r=0.86, p<0.001$ ), meaning that, all waves considered, NREM segments with large frontal slow waves also tend to contain large occipital slow waves. Next, we correlated the amplitude of the large slow waves (above the 75th amplitude percentile) in the frontal region of interest with the amplitude of slow waves in the occipital region of interest (without an amplitude threshold). Here a significant negative correlation emerged (Spearman rank correlation coefficient $r=$ $-0.19, p=0.002)$. It therefore appears that the larger the subset of high-amplitude slow waves in the frontal cortex, the smaller the slow waves in the occipital cortex.

These results suggest that there are two distinct populations of slow waves that differentially relate to dream reports and whose amplitudes are anticorrelated (Fig. 7). To achieve a more accurate and topography-independent classification of the two types of slow waves, for further analyses we used a previously described approach (Bernardi et al., 2018) that divides slow waves into putative type I slow waves (minority of large and steep slow waves with frontocentral involvement) and type II slow waves (majority of smaller, shallower, diffusely distributed slow waves) based on a synchronization index taking into account their amplitude and slope (for details, see Materials and Methods). This method is based on a single temporal reference representing all sources ("negative envelope" of the signal), and can thus classify slow waves regardless of their origin and scalp distribution. Because these analyses are mainly aimed at investigating how distinctive properties of type I slow waves relate to dream experiences, a stringent arbitrary threshold was applied to separate type I from potentially large type II slow waves. More specifically, only slow waves with a synchronization index $>4$ standard MADs from the median of all slow waves were considered type I slow waves, while the remainder of slow waves were considered type II slow waves. The large majority of slow waves classified as type I according to this method ( $95.0 \pm 4.5 \%$, mean across all channels) had an amplitude above the 75th percentile (i.e., were classified as "large" based on the amplitude criterion used in previously described analyses (Fig. 8A). In contrast, only about half of type II slow waves $(52.6 \pm 4.1 \%)$ had a large amplitude.

We then computed the ratio between type I and type II slow waves for each NREM period preceding awakenings, and found that it was significantly different among DE, DEWR, and NE (one-way repeated-measures ANOVA, $F_{(2,12)}=5.795, p=$ $0.008)$, with $\mathrm{DE}(0.10 \pm 0.01)$ having a significantly higher ratio compared with DEWR $(0.05 \pm 0.01, p=0.04$, paired two-tailed $t$ test $)$ and NE $(0.04 \pm 0.01, p=0.02)$, while the latter two categories did not differ significantly ( $p=0.4$; Fig. $8 B$ ).

Next, we explored the direction of the negative association we observed between the amplitude of large frontal slow waves and occipital slow waves (Fig. 7). More specifically, we wanted to know whether type I slow waves were more likely to occur on an EEG background of small slow waves or whether they induced reductions of slow-wave amplitude, particularly in posterior areas. To this aim, we first examined the correlation between SWA in the $6 \mathrm{~s}$ preceding each slow wave and the synchronization index of that slow wave. This analysis revealed that type I slow waves were more likely to be large and steep (i.e., to have a higher 
A

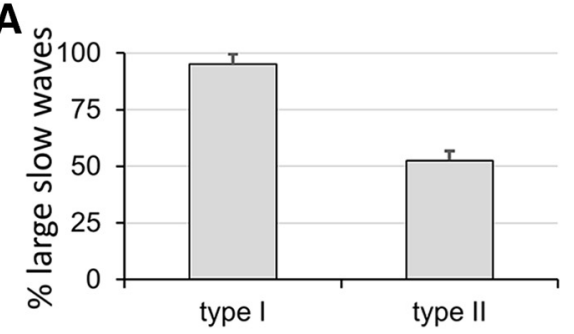

B

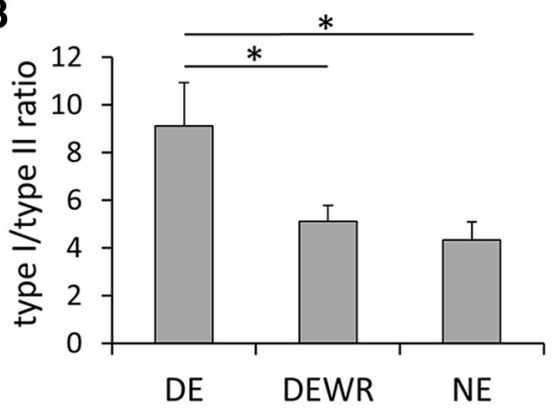

C

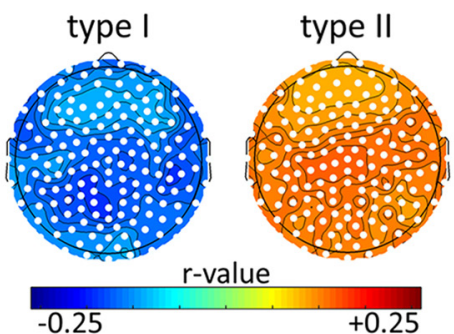

D
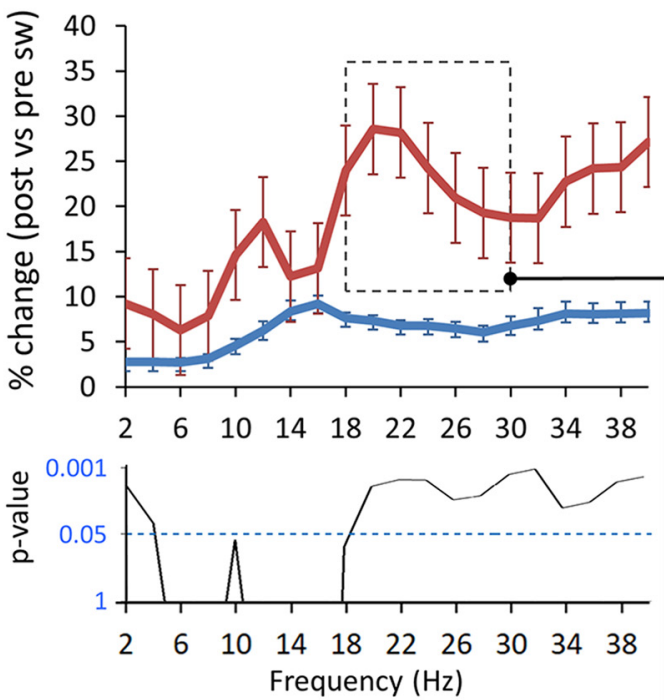

$\mathbf{E}$

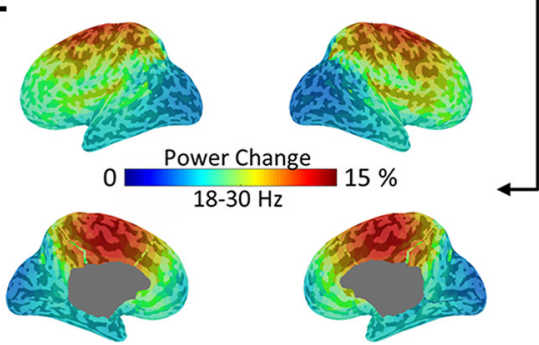

correlation delta power - synchronization index

Figure 8. Type I and type II slow-wave characteristics. A, Proportion of slow waves classified as type I (left) or type II (right) based on synchronization efficiency that were also defined as large based on the channel-by-channel amplitude criterion ( $>75$ th percentile; for comparison, slow waves were identified in a $250 \mathrm{~ms}$ time window centered on the peak of the type I/II slow wave). Each bar in the graph represents the average (\%) across subjects \pm SD. B, Type I/type Il ratio for the 60 s preceding DE, DEWR, and NE (mean and SEM). Asterisks indicate statistically significant differences at $p<0.05$ (paired two-tailed $t$ tests). C, Correlation between low-frequency spectral power in the $1-4 \mathrm{~Hz}$ range (in the $6 \mathrm{~s}$ preceding the slow wave) and the synchronization index (reflecting slow-wave amplitude and slope) for type I and type II slow waves (Spearman rank correlation coefficient). Type I and type Il slow waves were separated according to their synchronization index (for details, see Materials and Methods). Electrodes within a cluster showing a statistically significant effect are marked in white ( $p<0.05$, cluster-based correction for multiple comparisons). $\boldsymbol{D}$, Spectral power changes (\%) induced by type I and type II slow waves in a frontal electrode cluster (Fz and immediately neighboring electrodes). Spectral power in the $6 \mathrm{~s}$ following the slow wave was compared with spectral power in the $6 \mathrm{~s}$ preceding each slow wave for different frequency bands $(1-40 \mathrm{~Hz}$; resolution of $2 \mathrm{~Hz}$ bins). Bottom row, $p$ Values for the comparison between PSD changes induced by type I and type II slow waves (paired two-tailed $t$ tests). $\boldsymbol{E}$, Cortical distribution of spectral power changes in the $18-30 \mathrm{~Hz}$ for type I slow waves at the source level.

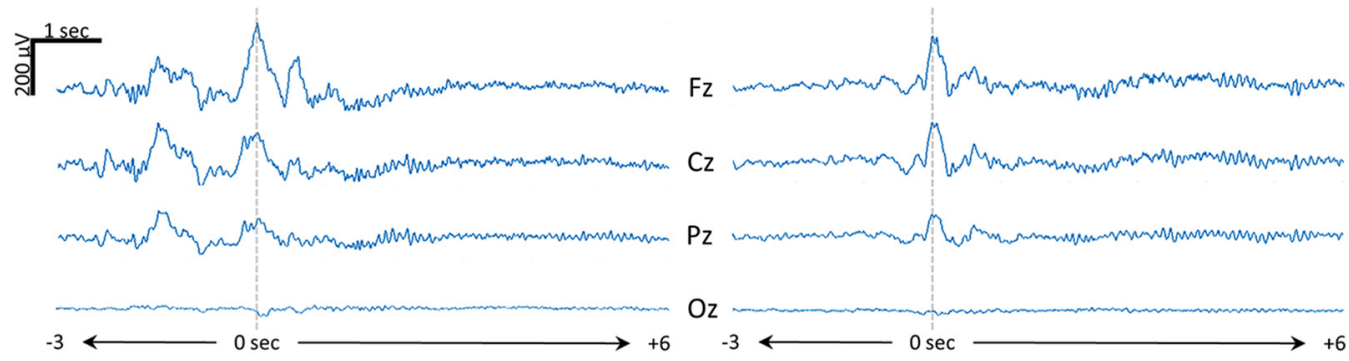

Figure 9. Representative examples of high-frequency increases following type I slow waves. Time 0 corresponds to the maximum negative peak of the type I slow wave. Four representative midline channels are displayed [Fz (frontal), $\mathrm{Cz}$ (central), $\mathrm{Pz}$ (parietal), and $\mathrm{Oz}$ (occipital)], referenced to the average of two mastoid channels.

synchronization index) if they occurred on a background of low SWA, while for type II slow waves the opposite effect was true (Fig. $8 C$ ). We then examined changes in spectral power induced by type I and type II slow waves (in the $6 \mathrm{~s}$ following the slow wave). We found that, on average, type I slow waves induced increases in spectral power in all frequency bands, with a small peak in the $10-12 \mathrm{~Hz}$ range and a larger peak in the $18-30 \mathrm{~Hz}$ range (Fig. $8 D$ ). A source-modeling analysis revealed that the
$18-30 \mathrm{~Hz}$ increases following type I slow waves peaked in frontocentral regions including the medial primary motor cortex and the mid-cingulate cortex (top 5\% of voxels; Fig. 8E). EEG examples of high-frequency increases following type I slow waves are shown in Figure 9. For type II slow waves, these changes were less pronounced and peaked in the fast spindle range $(\sim 13-14 \mathrm{~Hz})$. Type I slow waves induced significantly larger power increases in the $0-2 \mathrm{~Hz}$ and $18-40 \mathrm{~Hz}$ frequency ranges compared with type 

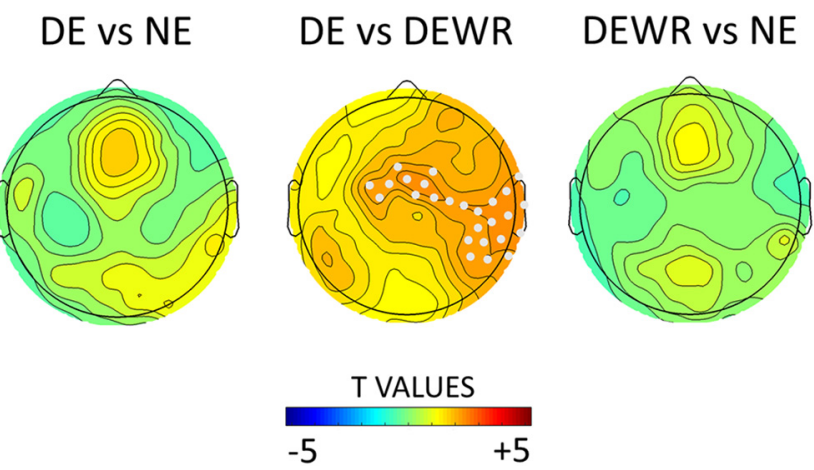

Figure 10. Topographical distribution of $t$ values for the contrast in $18-30 \mathrm{~Hz}$ changes induced by type I slow waves between dream experiences (DEs), no experiences (NEs) (left), DE and dream experiences without recall of content (DEWR) (middle), and DEWR and NE (right), averaged over the last $60 \mathrm{~s}$ before the awakening. Electrodes within a cluster showing a statistically significant effect are marked in white $(p<0.05$, cluster-based correction for multiple comparisons, two-tailed paired $t$ tests: $n=12$ subjects for $\mathrm{DE} ; n=11$ subjects for $\mathrm{NE} ; n=13$ subjects for DEWR).

II slow waves (Fig. 8D). Importantly, overall, neither type I nor type II slow waves induced decreases in SWA. These results show that type I slow waves tend to occur when SWA is low, but do not appear to consistently induce reductions in SWA. Instead, they are often followed by high-frequency power increases that look like "microarousals" (Fig. 9) according to sleep-scoring criteria (Iber et al., 2007).

We then asked whether the high-frequency increases following type I slow waves differed among DE, DEWR, and NE. We found that type I slow waves induced significantly stronger increases in high-frequency activity $(18-30 \mathrm{~Hz})$ in central regions (with a right-sided lateralization) when subjects could recall the content of the dream (DE) as opposed to when they could not (DEWR; Fig. 10).

\section{Spindles and dreaming}

Finally, we examined how sleep spindles relate to dreaming. We found that spindles preceding DE, compared with NE, were more numerous and had a higher frequency (Fig. 11). There were significantly more fast spindles preceding reports of DE, and these differences were relatively diffuse. However, a contrast between DEWR and NE showed that dreaming per se (regardless of the ability to the recall the content of the dream), was associated with significantly more fast spindles and fewer slow spindles in a central posterior region of the brain. The DE versus DEWR contrast did not show any significant differences (data not shown).

\section{Discussion}

\section{Slow-wave characteristics and dreaming}

The EEG slow wave of sleep occurs when thalamocortical neurons become bistable and start to oscillate between two states, each lasting a few hundred milliseconds: a hyperpolarized "down-state," during which neurons are silent (off-period), and a depolarized "up-state" (on-period) characterized by neuronal firing (Steriade et al., 2001; Nir et al., 2011). In the present study, we were able to link specific slow-wave characteristics to dream experiences. We found that dreaming, as opposed to no experiences (unconsciousness), was associated with fewer slow waves, which were smaller and shallower, and had a tendency to display a larger number of negative peaks. Large-scale computer simulations (Esser et al., 2007), local field potential studies in rodents (Vyazovskiy et al., 2007), and EEG studies in humans (Riedner et al., 2007) have revealed that the amplitude of slow waves reflects the number of neuronal populations that simultaneously enter a down-state and are thus in phase with each other, while the first and second slopes of the slow waves are a measure of the speed with which neuronal populations transition into the down-state and up-state, respectively. Finally, the number of negative peaks of a slow wave is related to the spatial synchrony of slow-wave generation, with multipeak slow waves resulting from an asynchronous generation of slow waves in distant cortical regions. Our findings thus indicate that reports of unconsciousness are more likely when large neuronal populations simultaneously and rapidly enter a down-state that is synchronized across central posterior cortical regions. Several studies have suggested that the off-period associated with slow waves represents the fundamental mechanism by which consciousness is lost during sleep. It has been shown that the slow wave-like response induced by TMS during sleep leads to a breakdown of cortical effective connectivity among specialized thalamocortical regions (Massimini et al., 2005, 2010), thereby impairing information integration, which has been proposed as a prerequisite for consciousness (Tononi, 2008). The neuronal off-period associated with the slow wavelike response to cortical stimulation leads to an interruption of deterministic interactions, indicated by the loss of causal effects between the stimulation and brain activity resuming after the off-period (measured by a phase locking index; Pigorini et al., 2015). Our results are also consistent with those of a previous study (Nieminen et al., 2016) showing that within NREM sleep, TMS applied to posterior cortical regions evokes a larger negative deflection and a shorter phase-locked response when subjects reported unconsciousness compared with when they reported dreaming.

\section{Topographical distribution of slow waves and dreaming}

Differences in slow-wave characteristics between dreaming and unconsciousness, especially amplitude and slope, were not uniformly distributed across the cortical surface, but were most consistent in central and posterior regions. This is in line with our recent study, in which we showed that dream reports were preceded by lower SWA in a posterior "hot zone" of the brain, comprising the medial and lateral occipital lobe and extending superiorly to the precuneus and posterior cingulate gyrus (Siclari et al., 2017). Several imaging modalities converge to indicate that the posterior cingulate gyrus is one of the most consistent cerebral "hubs," connecting many different brain areas (de Pasquale et al., 2018). The occurrence of off-states in this region may thus lead to a breakdown of consciousness because it may disrupt connectivity with many relatively distant areas of the brain. These results are also in line with reports of cessation of dreaming after lesions of the inferior parietal and occipital cortex (Wilbrand, 1892; Murri et al., 1985; Solms, 1997; Bischof and Bassetti, 2004), and with the observation that in the course of development, dreaming appears to be closely related with the maturation of visuospatial skills, which depend on posterior (parietal) cortical areas (Foulkes, 1999). In the frontal cortex on the other hand, slow waves were less consistently associated with unconsciousness than in central and posterior brain regions. When considering high-amplitude slow waves, we even found that the opposite was true: these high-amplitude slow waves were larger and steeper in frontal regions when they preceded reports of dream experiences. 


\section{DREAM EXPERIENCE VS NO EXPERIENCE}

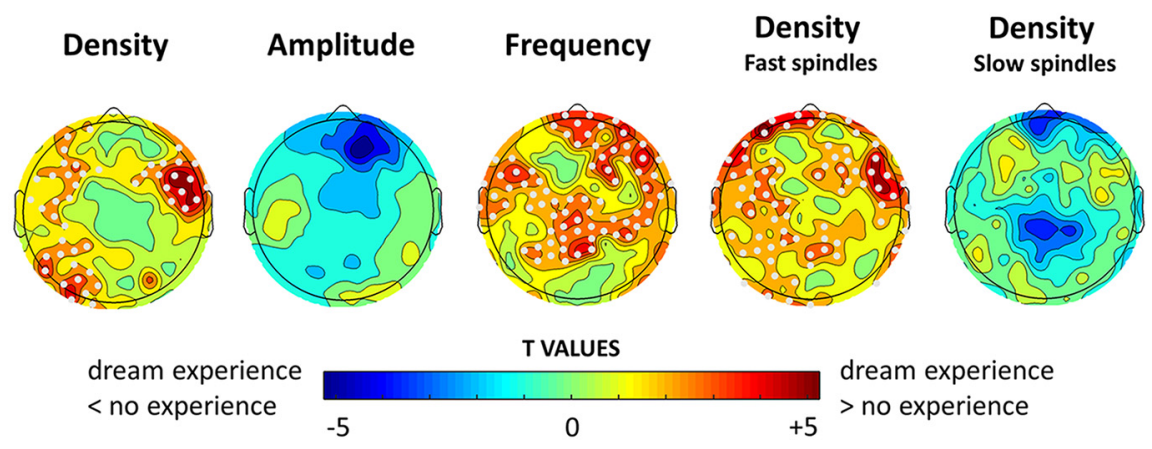

DREAM EXPERIENCE W/O RECALL OF CONTENT VS NO EXPERIENCE

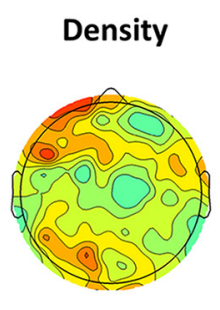

dream experience $w / o$ recall of content

$<$ no experience
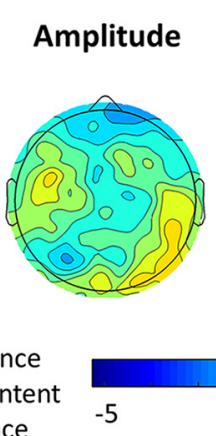

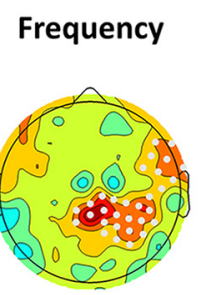

T VALUES
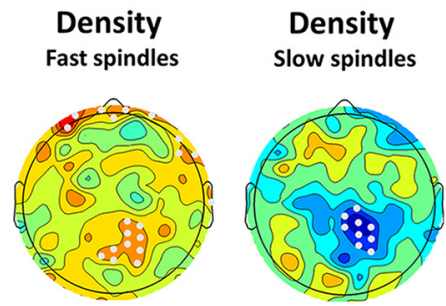

dream experience $w / o$ recall of content

$>$ no experience
Figure 11. Top row, Topographical distribution of $t$ values for the contrast between dream experiences and no experiences for different spindle parameters (60 s before awakening). Electrodes within a cluster showing a statistically significant effect are marked in white ( $p<0.05$, cluster-based correction for multiple comparisons, two-tailed paired $t$ tests; $n=12$ subjects) are marked in white. Bottom row, Same as the top row for dream experiences without recall of content vs no experience.

mation (Jones and Yang, 1985), another arousal-promoting structure, and the ventromedial thalamic nucleus (Desbois and Villanueva, 2001; Kuramoto et al., 2015). Very large-amplitude slow waves are specifically associated with fMRI brainstem activations including the locus ceruleus (Dang-Vu et al., 2008), and it is well known that K-complexes, which share many properties with type I slow waves (Siclari et al., 2014), can be induced by peripheral sensory stimulations. Finally, type I slow waves tend to be followed by increases in high-frequency spectral power that peak in frontomedial regions (Fig. $8 E$ ), often fulfill the criteria for microarousals (Iber et al., 2007; Fig. 9), and herald the successful recall of dream content (Fig. 10). The topographic distribution of these high-frequency increases (Fig. $8 D$ ) closely matches the distribution of high-frequency activity that has previously been shown to distinguish dreams with and without recalled dream content (Siclari et al., 2017). Interestingly and in line with these findings, intrasleep awakenings are higher in frequent dream recallers compared with infrequent dream recallers (Ruby et al., 2013; Eichenlaub et al., 2014). Increases in high-frequency power may thus reflect the intermittent activation of arousal systems and in particular surges in noradrenergic activity occurring in NREM sleep (Aston-Jones and

\section{Type I and type II slow waves}

We recently obtained evidence for two types of synchronization processes underlying slow waves in the transition to sleep: a presumably subcorticocortical synchronization process giving rise to isolated, very large and steep slow waves with a frontocentral involvement (type I slow waves), and a presumably corticocortical synchronization process underlying smaller slow waves, with more variable cortical origins (type II slow waves; Siclari et al., 2014). These two processes are temporally dissociated in the falling asleep period in adults, but are also present during stable sleep (Bernardi et al., 2018). The fact that reports of dreaming are particularly likely when large, steep, and frontal type I slow waves occur could be explained by several findings. First, type I slow waves are more likely to be large and steep when they occur on an EEG background of low SWA (Fig. 8C). Therefore, the presence of frontal type I slow waves may indicate that most cortical regions, and in particular posterior areas, are in a state of relatively low bistability and are more likely to contribute to conscious experiences. Second, several lines of evidence suggest that type I slow waves may be related to arousal systems. Source-modeling analyses have revealed that they originate preferentially in sensorimotor regions and in the posterior-medial parietal cortex, and that they involve primarily frontomedial regions (Siclari et al., 2014). The regions of origin are the brain areas with the highest noradrenergic innervation in the human and monkey cortex (Gaspar et al., 1989; Javoy-Agid et al., 1989; Lewis and Morrison, 1989). Cortical projections preferentially targeting the frontal medial area, consistent with the medial frontal involvement, have been described for the pontine and mesencephalic reticular for-
Bloom, 1981). Notably, noradrenaline favors memory encoding and consolidation in both wakefulness (Roozendaal and McGaugh, 2011) and sleep (Gais et al., 2011).

\section{Spindles and dreaming}

Our findings suggest that dreaming is more likely to occur in the presence of fast spindles in a central and posterior cortical region, while reports of no experience preferentially occur in the presence of slow spindles in the same areas. These findings are consistent with the recent observation that subjects who reported a high number of dreams had faster spindles (Nielsen et al., 2016). Spindle frequency has been related to the level of thalamic hyperpolarization and typically decreases in the course of the falling asleep period (Himanen et al., 2002; Andrillon et al., 2011; Siclari et al., 2014), along with increasing levels of thalamic hyperpolarization (Andrillon et al., 2011) and SWA. One possibility is that these findings indirectly reflect differences in slow-wave characteristics. Spindles occurring during the positive-to-negative deflection of the slow wave (progressive cortical hyperpolarization) tend to be slower than spindles occurring during the negative-topositive phase of the EEG slow wave (transition to depolarized cortical up-state; Molle et al., 2011; Siclari et al., 2014). It is thus conceivable that when slow waves are sparse and shallow and are associated with longer up-states, fast spindles are more likely to occur. The fact that both slow-wave and spindle differences were most consistent over the same central posterior brain areas would support such an interpretation. 


\section{Limitations}

It should be noted that our distinction between type I and type II slow waves, although supported by different observations, is based on an arbitrary cutoff, as there is currently no better way to separate the two types of slow waves in stable sleep. Therefore, future studies using techniques allowing direct imaging of arousal-related subcortical structures will be necessary to validate this separation and the results.

\section{Summary and conclusions}

Here we show that dreaming in NREM sleep is determined by the proportion and distribution of two distinct types of slow waves. Dream experiences are more likely to occur when the majority of slow waves (type II slow waves) are small, sparse, and shallow, especially in posterior brain regions. The content of dream experiences is more likely to be reported if, in addition, highamplitude slow waves (type I slow waves) occur in frontocentral brain regions and are followed by high-frequency increases (local microarousals). These results suggest that the capacity of the brain to generate experiences during sleep is reduced in the presence of large type II slow waves in posterior and central brain regions, and that dream recall may be facilitated by the intermittent activation of arousal systems during NREM sleep (associated with type I slow waves).

\section{References}

Anderer P, Klosch G, Gruber G, Trenker E, Pascual-Marqui RD, Zeitlhofer J, Barbanoj MJ, Rappelsberger P, Saletu B (2001) Low-resolution brain electromagnetic tomography revealed simultaneously active frontal and parietal sleep spindle sources in the human cortex. Neuroscience 103: 581-592. CrossRef Medline

Andrillon T, Nir Y, Staba RJ, Ferrarelli F, Cirelli C, Tononi G, Fried I (2011) Sleep spindles in humans: insights from intracranial EEG and unit recordings. J Neurosci 31:17821-17834. CrossRef Medline

Antrobus J, Kondo T, Reinsel R, Fein G (1995) Dreaming in the late morning: summation of REM and diurnal cortical activation. Conscious Cogn 4:275-299. CrossRef Medline

Aserinsky E, Kleitman N (1955) Two types of ocular motility occuring during sleep. J Appl Physiol 8:11-18. CrossRef Medline

Aston-Jones G, Bloom FE (1981) Activity of norepinephrine-containing locus ceruleus neurons in behaving rats anticipates fluctuations in the sleepwaking cycle. J Neurosci 1:876-886. CrossRef Medline

Bernardi G, Cecchetti L, Siclari F, Buchmann A, Yu X, Handjaras G, Bellesi M, Ricciardi E, Kecskemeti SR, Riedner BA, Alexander AL, Benca RM, Ghilardi MF, Pietrini P, Cirelli C, Tononi G (2016) Sleep reverts changes in human gray and white matter caused by wake-dependent training. Neuroimage 129:367-377. CrossRef Medline

Bernardi G, Siclari F, Handjaras G, Riedner BA, Tononi G (2018) Local and widespread slow waves in stable NREM sleep: evidence for distinct regulation mechanisms. Front Hum Neurosci 12:248. CrossRef Medline

Bischof M, Bassetti CL (2004) Total dream loss: a distinct neuropsychological dysfunction after bilateral PCA stroke. Ann Neurol 56:583-586. CrossRef Medline

Chellappa SL, Frey S, Knoblauch V, Cajochen C (2011) Cortical activation patterns herald successful dream recall after NREM and REM sleep. Biol Psychol 87:251-256. CrossRef Medline

Dang-Vu TT, Schabus M, Desseilles M, Albouy G, Boly M, Darsaud A, Gais S, Rauchs G, Sterpenich V, Vandewalle G, Carrier J, Moonen G, Balteau E, Degueldre C, Luxen A, Phillips C, Maquet P (2008) Spontaneous neural activity during human slow wave sleep. Proc Natl Acad Sci U S A 105: 15160-15165. CrossRef Medline

Delorme A, Makeig S (2004) EEGLAB: an open source toolbox for analysis of single-trial EEG dynamics including independent component analysis. J Neurosci Methods 134:9-21. CrossRef Medline

de Pasquale F, Corbetta M, Betti V, Della Penna S (2018) Cortical cores in network dynamics. Neuroimage 180:370-382. CrossRef Medline

Desbois C, Villanueva L (2001) The organization of lateral ventromedial thalamic connections in the rat: a link for the distribution of nociceptive signals to widespread cortical regions. Neuroscience 102:885-898. CrossRef Medline

Eichenlaub JB, Bertrand O, Morlet D, Ruby P (2014) Brain reactivity differentiates subjects with high and low dream recall frequencies during both sleep and wakefulness. Cereb Cortex 24:1206-1215. CrossRef Medline

Esposito MJ, Nielsen TA, Paquette T (2004) Reduced alpha power associated with the recall of mentation from stage 2 and stage REM sleep. Psychophysiology 41:288-297. CrossRef Medline

Esser SK, Hill SL, Tononi G (2007) Sleep homeostasis and cortical synchronization: I. Modeling the effects of synaptic strength on sleep slow waves. Sleep 30:1617-1630. CrossRef Medline

Ferrarelli F, Huber R, Peterson MJ, Massimini M, Murphy M, Riedner BA, Watson A, Bria P, Tononi G (2007) Reduced sleep spindle activity in schizophrenia patients. Am J Psychiatry 164:483-492. CrossRef Medline

Foulkes D (1999) Children's dreaming and the development of consciousness. Cambridge, MA: Harvard UP.

Funk CM, Honjoh S, Rodriguez AV, Cirelli C, Tononi G (2016) Local slow waves in superficial layers of primary cortical areas during REM sleep. Curr Biol 26:396-403. CrossRef Medline

Gais S, Rasch B, Dahmen JC, Sara S, Born J (2011) The memory function of noradrenergic activity in non-REM sleep. J Cogn Neurosci 23:2582-2592. CrossRef Medline

Gaspar P, Berger B, Febvret A, Vigny A, Henry JP (1989) Catecholamine innervation of the human cerebral cortex as revealed by comparative immunohistochemistry of tyrosine hydroxylase and dopamine-betahydroxylase. J Comp Neurol 279:249-271. CrossRef Medline

Himanen SL, Virkkala J, Huhtala H, Hasan J (2002) Spindle frequencies in sleep EEG show U-shape within first four NREM sleep episodes. J Sleep Res 11:35-42. CrossRef Medline

Huber R, Ghilardi MF, Massimini M, Tononi G (2004) Local sleep and learning. Nature 430:78-81. CrossRef Medline

Iber C, Ancoli-Israel S, Chesson A, Quan SF (2007) The AASM manual for the scoring of sleep and associated events: rules, terminology and technical specifications, Ed 1. Westchester, IL: American Academy of Sleep Medicine.

Javoy-Agid F, Scatton B, Ruberg M, L'Heureux R, Cervera P, Raisman R, Maloteaux JM, Beck H, Agid Y (1989) Distribution of monoaminergic, cholinergic, and GABAergic markers in the human cerebral cortex. Neuroscience 29:251-259. CrossRef Medline

Jones BE, Yang TZ (1985) The efferent projections from the reticular formation and the locus coeruleus studied by anterograde and retrograde axonal transport in the rat. J Comp Neurol 242:56-92. CrossRef Medline

Jung TP, Makeig S, Humphries C, Lee TW, McKeown MJ, Iragui V, Sejnowski TJ (2000) Removing electroencephalographic artifacts by blind source separation. Psychophysiology 37:163-178. CrossRef Medline

Kuramoto E, Ohno S, Furuta T, Unzai T, Tanaka YR, Hioki H, Kaneko T (2015) Ventral medial nucleus neurons send thalamocortical afferents more widely and more preferentially to layer 1 than neurons of the ventral anterior-ventral lateral nuclear complex in the rat. Cereb Cortex 25:221235. CrossRef Medline

Lewis DA, Morrison JH (1989) Noradrenergic innervation of monkey prefrontal cortex: a dopamine-beta-hydroxylase immunohistochemical study. J Comp Neurol 282:317-330. CrossRef Medline

Marzano C, Ferrara M, Mauro F, Moroni F, Gorgoni M, Tempesta D, Cipolli C, De Gennaro L (2011) Recalling and forgetting dreams: theta and alpha oscillations during sleep predict subsequent dream recall. J Neurosci 31:6674-6683. CrossRef Medline

Massimini M, Ferrarelli F, Huber R, Esser SK, Singh H, Tononi G (2005) Breakdown of cortical effective connectivity during sleep. Science 309: 2228-2232. CrossRef Medline

Massimini M, Ferrarelli F, Murphy M, Huber R, Riedner B, Casarotto S, Tononi G (2010) Cortical reactivity and effective connectivity during REM sleep in humans. Cogn Neurosci 1:176-183. CrossRef Medline

Molle M, Bergmann TO, Marshall L, Born J (2011) Fast and slow spindles during the sleep slow oscillation: disparate coalescence and engagement in memory processing. Sleep 34:1411-1421. CrossRef Medline

Monroe LJ, Rechtschaffen A, Foulkes D, Jensen J (1965) Discriminability of REM and NREM reports. J Pers Soc Psychol 2:456-460. Medline

Murri L, Massetani R, Siciliano G, Giovanditti L, Arena R (1985) Dream recall after sleep interruption in brain-injured patients. Sleep 8:356-362. CrossRef Medline

Nichols TE, Holmes AP (2002) Nonparametric permutation tests for func- 
tional neuroimaging: a primer with examples. Hum Brain Mapp 15:1-25. CrossRef Medline

Nielsen T, Carr M, Blanchette-Carrière C, Marquis L, Dumel G, Solomonova E, Julien S, Picard-Deland C, Paquette T (2016) NREM sleep spindles are associated with dream recall. Sleep Spindles Cortical Up States 1:27-41. CrossRef

Nieminen JO, Gosseries O, Massimini M, Saad E, Sheldon AD, Boly M, Siclari F, Postle BR, Tononi G (2016) Consciousness and cortical responsiveness: a within-state study during non-rapid eye movement sleep. Sci Rep 6:30932. CrossRef Medline

Nir Y, Staba RJ, Andrillon T, Vyazovskiy VV, Cirelli C, Fried I, Tononi G (2011) Regional slow waves and spindles in human sleep. Neuron 70: 153-169. CrossRef Medline

Oudiette D, Dealberto MJ, Uguccioni G, Golmard JL, Merino-Andreu M, Tafti M, Garma L, Schwartz S, Arnulf I (2012) Dreaming without REM sleep. Conscious Cogn 21:1129-1140. CrossRef Medline

Pigorini A, Sarasso S, Proserpio P, Szymanski C, Arnulfo G, Casarotto S, Fecchio M, Rosanova M, Mariotti M, Lo Russo G, Palva JM, Nobili L, Massimini M (2015) Bistability breaks-off deterministic responses to intracortical stimulation during non-REM sleep. Neuroimage 112:105113. CrossRef Medline

Riedner BA, Vyazovskiy VV, Huber R, Massimini M, Esser S, Murphy M, Tononi G (2007) Sleep homeostasis and cortical synchronization: III. A high-density EEG study of sleep slow waves in humans. Sleep 30:16431657. CrossRef Medline

Roozendaal B, McGaugh JL (2011) Memory modulation. Behav Neurosci 125:797-824. CrossRef Medline

Ruby P, Blochet C, Eichenlaub JB, Bertrand O, Morlet D, Bidet-Caulet A (2013) Alpha reactivity to first names differs in subjects with high and low dream recall frequency. Front Psychol 4:419. CrossRef Medline
Siclari F, Larocque JJ, Postle BR, Tononi G (2013) Assessing sleep consciousness within subjects using a serial awakening paradigm. Front Psychol 4:542. CrossRef Medline

Siclari F, Bernardi G, Riedner B, LaRocque J, Benca MR, Tononi G (2014) Two distinct synchronization processes in the transition to sleep: a highdensity electroencephalographic study. Sleep 37:1621-1637. CrossRef Medline

Siclari F, Baird B, Perogamvros L, Bernardi G, LaRocque JJ, Riedner B, Boly M, Postle BR, Tononi G (2017) The neural correlates of dreaming. Nat Neurosci 20:872-878. CrossRef Medline

Solms M (1997) The neuropsychology of dreams: a clinico-anatomical study. Mahwah, NJ: Erlbaum.

Solms M (2000) Dreaming and REM sleep are controlled by different brain mechanisms. Behav Brain Sci 23:843-850. CrossRef Medline

Steriade M, Timofeev I, Grenier F (2001) Natural waking and sleep states: a view from inside neocortical neurons. J Neurophysiol 85:1969-1985. CrossRef Medline

Stickgold R, Malia A, Fosse R, Propper R, Hobson JA (2001) Brain-mind states: I. Longitudinal field study of sleep/wake factors influencing mentation report length. Sleep 24:171-179. CrossRef Medline

Tononi G (2008) Consciousness as integrated information: a provisional manifesto. Biol Bull 215:216-242. CrossRef Medline

Vyazovskiy VV, Riedner BA, Cirelli C, Tononi G (2007) Sleep homeostasis and cortical synchronization: II. A local field potential study of sleep slow waves in the rat. Sleep 30:1631-1642. CrossRef

Wilbrand H (1892) Ein Fall von Seelenblindheit und Hemianopsie mit Sektionsbefund. Deutsche Zeitschrift für Nervenheilkunde 2:361-387.

Williamson PC, Csima A, Galin H, Mamelak M (1986) Spectral EEG correlates of dream recall. Biol Psychiatry 21:717-723. CrossRef Medline 